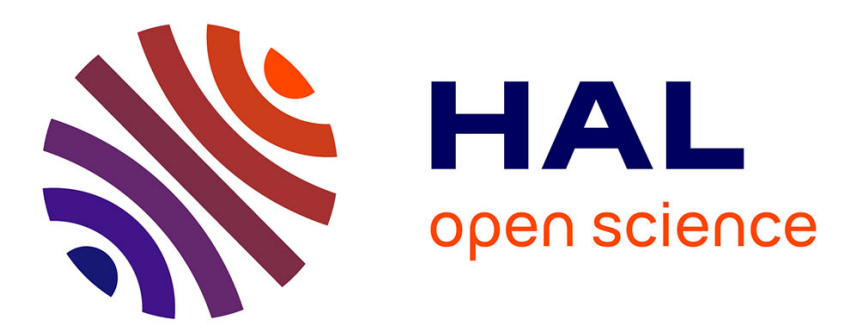

\title{
Allocation and Scheduling of Firefighting Units in Large Petrochemical Complexes
}

Khaled Alutaibi, Abdullah Alsubaie, Jose Marti

\section{To cite this version:}

Khaled Alutaibi, Abdullah Alsubaie, Jose Marti. Allocation and Scheduling of Firefighting Units in Large Petrochemical Complexes. 9th International Conference on Critical Infrastructure Protection (ICCIP), Mar 2015, Arlington, VA, United States. pp.263-279, 10.1007/978-3-319-26567-4_16 . hal01431006

\section{HAL Id: hal-01431006 \\ https://hal.inria.fr/hal-01431006}

Submitted on 10 Jan 2017

HAL is a multi-disciplinary open access archive for the deposit and dissemination of scientific research documents, whether they are published or not. The documents may come from teaching and research institutions in France or abroad, or from public or private research centers.
L'archive ouverte pluridisciplinaire HAL, est destinée au dépôt et à la diffusion de documents scientifiques de niveau recherche, publiés ou non, émanant des établissements d'enseignement et de recherche français ou étrangers, des laboratoires publics ou privés. 


\title{
Chapter 16
}

\section{ALLOCATION AND SCHEDULING OF FIREFIGHTING UNITS IN LARGE PETROCHEMICAL COMPLEXES}

\author{
Khaled Alutaibi, Abdullah Alsubaie and Jose Marti
}

\begin{abstract}
Fire incidents in large petrochemical complexes such as oil refineries cause heavy losses. Due to the strong interdependencies that exist among units in these industrial complexes, planning an efficient response is a challenging task for firefighters. The task is even more challenging during multiple-fire incidents. This chapter describes a firefighting decision support system that helps conduct efficient responses to fire incidents. The decision support system optimizes the allocation of firefighting units in multiple-fire incidents with the objective of minimizing the economic impact. In particular, the system considers infrastructure interdependencies in estimating the damage associated with a given fire scenario, calculates the resulting economic losses and determines the optimal assignment of available firefighters. The decision support system can be used before an incident for training and planning, during an incident for decision support or after an incident for evaluating suppression strategies.
\end{abstract}

Keywords: Firefighting, industrial fires, decision support system

\section{Introduction}

The principal goals of firefighting are to save lives, contain the fire to reduce the risk of a wider impact and balance the risk of environmental impact versus putting out the fire. Decisions about allocating resources such as firefighters, bulldozers, fire trucks, helicopters and air tankers are essential during fires as well as extreme events such as earthquakes and floods. These events can cause large numbers of deaths and injuries, huge economic losses and interruptions of basic services. Mihailidou et al. [24] have examined 319 industrial accidents, about $30 \%$ of which were fires. The 319 accidents occurred in 52 countries; $39 \%$ of the accidents occurred in the United States. 
During a fire incident, the principal objective of firefighters - after saving lives - is to minimize incident losses. According to Hall [11], the "total cost" of a fire is defined as the direct and indirect losses due to the fire plus the cost of provisions to mitigate the losses. The U.S. National Fire Protection Association (NFPA) reported that the estimated fire-related economic loss in 2011 was $\$ 14.9$ billion. These losses include property damage (direct losses) and business interruption (indirect losses); $65 \%$ of the business interruption cost ( $\$ 9.7$ billion) was due to fires in industrial properties [11]. Due to the difficulty of pre-calculating the indirect losses, current firefighting practices target the size of a fire to reduce property damage. However, the analysis of fires reveals that a low correlation exists between the property damage cost and the business interruption cost [11]. In many cases, the business interruption cost far exceeds the direct property loss. Hall [11] states, "Sometimes, though, it can be difficult to determine what the true net loss due to business interruption is." The research described in this chapter considers the indirect loss resulting from business interruption as a significant factor when allocating firefighting resources.

According to the National Fire Protection Association [26], the number of units assigned to respond to a fire incident should be determined by risk analysis and/or pre-fire planning. Typically, unit allocation decisions are made by fire department experts based on the available information about the incident and their incident handling experience. The size of a fire is usually the major factor in assigning the number of units. In the case of industrial incidents, other factors such as economic impact and the criticality of the site are often not taken into account. Better incident response can be achieved by allocating an optimum number of firefighting units to a critical site.

In multiple-fire incidents, as opposed to single-fire incidents, fire department officials must necessarily alter their normal response assignments [30]. The special assignments require deep understanding of the infrastructure systems and their interdependencies. Fire department officials can benefit greatly from a decision support system that can help them plan better responses to large fire incidents that affect critical facilities.

This chapter describes a firefighting decision support system (FFDSS) that is designed to enable fire departments to optimize the allocation of firefighting units in multiple-fire incidents. The system takes into account infrastructure interdependencies in evaluating the economic impacts of incidents. The system uses infrastructure interdependency modeling to evaluate the economic impact of a fire incident and determines the assignment of firefighting units using an optimization agent that leverages a reinforcement learning algorithm. The decision support system can be used before a fire incident for training and planning, during a fire for optimizing the response or after a fire for evaluating suppression strategies.

This research uses a case study involving a petrochemical complex, which is an excellent example of an interdependent system. Petrochemical production processes are modeled and multiple-fire incidents are simulated by the decision 
support system. After computing the economic loss, a software agent is used to optimize the global objective by dynamically assigning firefighting units to the most critical fires. The decision support system can be extended to other resource allocation problems such as maintenance crew dispatching, warehouse location placement and other applications in similar interdependent environments.

\section{2. $\quad$ Related Work}

The key challenge in firefighting operations during a large incident is to efficiently utilize the available resources to reduce the impact of the fire. Over the years, researchers have addressed this challenge by designing fire decision support systems that model fire behavior and facilitate dispatch decisions, impact assessment and process optimization. Prominent fire decision support systems include LANIK [21], DEDICS [28] and WFDSS [7]. However, most of the systems focus on wildfires and offer limited intelligent decision making support for allocating the available resources $[2,10]$.

Several models have been developed for fire behavior prediction, including BEHAVE [1], FARSITE [6], HFire [25] and Prometheus [32]. However, the models only focus on fire behavior simulation using heat and smoke sources [4]. Moreover, the optimization of firefighting resources and the simulation of firefighting operations are developed separately and are not integrated [13]. In contrast, the decision support system described in this chapter integrates these components in a unifying framework.

Most of the existing fire decision models focus on the initial assignment of resources without dynamically adjusting the assignment [3]. The proposed decision support system, on the other hand, makes assignment decisions dynamically in line with the expected losses, thereby reflecting the long-term consequences of fire incidents. The system is also designed to deal with all types of fires, including wildfires. Moreover, its open architecture facilitates integration with other fire simulators and models.

A survey of the recent literature reveals that several simulation and optimization models have been integrated to support dispatching decisions in firefighting operations. Petrovic et al. [29] have developed a simulation-based model using stochastic processes and queuing theory to represent wildfire dynamics and allocate limited resources during fire suppression. Fried et al. [8] have proposed an integrated model for allocating firefighter resources and evaluating dispatching rules. Other researchers $[5,14,27]$ have also integrated fire behavior simulation and optimization to help allocate firefighting resources. $\mathrm{Hu}$ and Ntaimo [13] have developed an agent-based discrete event simulation model that simulates fire suppression based on dispatching plans from a stochastic optimization model. Lee et al. [20] have developed a model that combines optimization with stochastic simulation to assign resources (by type) that must arrive at a fire within a specified time and a given budget.

Finally, HomChaudhuri [12] has developed an intelligent resource allocation system that minimizes the damage due to wildfires. The system uses a genetic 


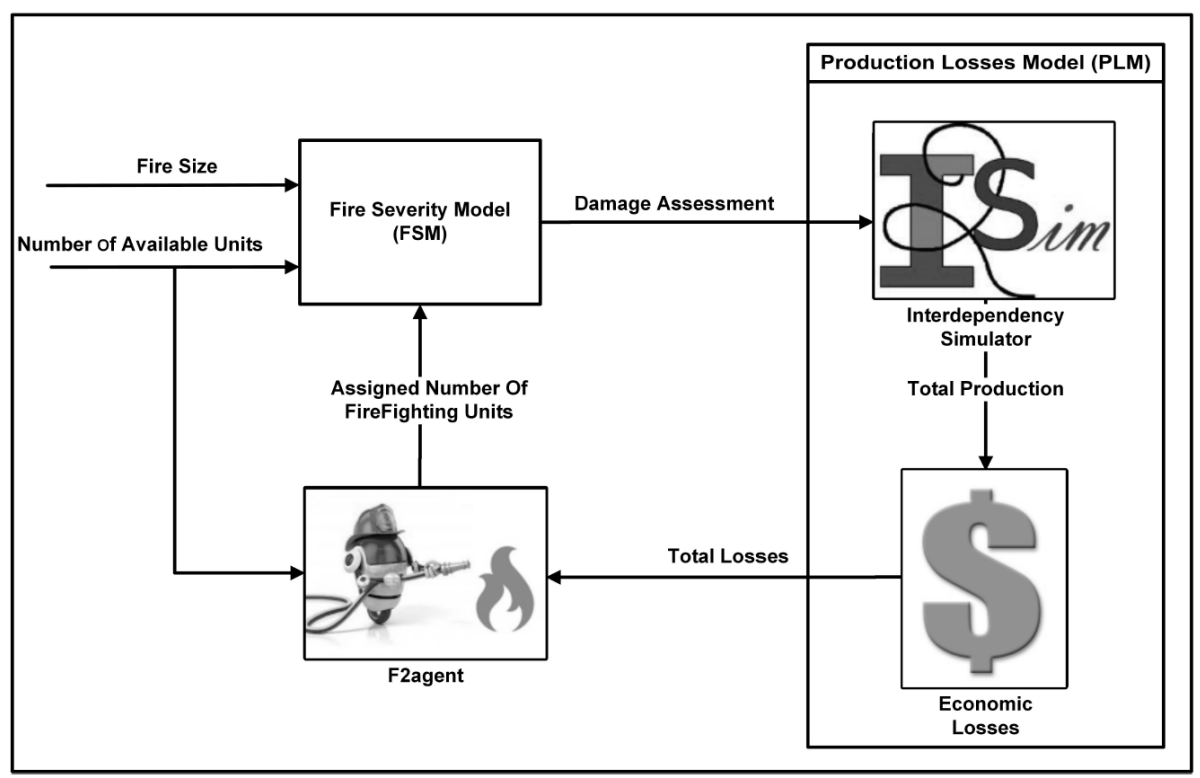

Figure 1. Firefighting decision support system architecture.

algorithm to determine the optimal placement of firefighting crews. However, this system, like other firefighting decision support systems, is limited to a specific type of fire and cannot handle interdependent infrastructures. In contrast, the firefighting decision support system described in this work considers the interdependencies underlying firefighting operations. This assists decision makers in allocating the optimal number of firefighting units during single- or multiple-fire incidents to minimize the overall cost (direct and indirect) as well as the long-term consequences.

\section{Proposed Decision Support System}

This section describes the proposed firefighting decision support system, which is designed to assist decision makers in allocating the optimal number of firefighting units during multiple-fire incidents in interdependent infrastructure environments. The system can be used before an incident for training and planning, during an incident for decision support or after an incident for evaluating suppression strategies.

The proposed firefighting decision support system has three main components: (i) a fire severity model (FSM) for simulating fire behavior and damage to an industrial complex; (ii) a production loss model for evaluating the economic impact of each decision on the production output of the industrial complex; and (iii) an optimization agent (F2agent) for optimizing the assignment of firefighting units. Figure 1 presents the architecture of the decision support system. 
Table 1. Firefighter assessment matrix.

\begin{tabular}{lcccccc}
\hline & \multicolumn{5}{c}{ Assigned Firefighters (man-hours) } \\
\cline { 2 - 7 } & No. Units & 4 & 8 & 12 & 16 & 20 \\
\cline { 2 - 7 } & Man-Hours & 20 & 40 & 60 & 80 & 100 \\
\cline { 2 - 7 } & Work Hours & & Fire Duration (hh:mm:ss) & \\
\hline Catastrophic & 600 & $30: 00: 00^{5}$ & $15: 00: 00^{5}$ & $10: 00: 00^{4}$ & $07: 30: 00^{3}$ & $06: 00: 00^{2}$ \\
\hline Critical & 300 & $15: 00: 00^{5}$ & $07: 30: 00^{4}$ & $05: 00: 00^{3}$ & $03: 45: 00^{2}$ & $03: 00: 00^{1}$ \\
\hline Marginal & 150 & $07: 30: 00^{4}$ & $03: 45: 00^{3}$ & $02: 30: 00^{2}$ & $01: 50: 00^{1}$ & $01: 30: 00^{1}$ \\
\hline Negligible & 75 & $03: 45: 00^{3}$ & $01: 50: 00^{2}$ & $01: 15: 00^{1}$ & $01: 00: 00^{1}$ & $00: 45: 00^{1}$ \\
\hline
\end{tabular}

\subsection{Fire Severity Model}

The fire severity model is used to estimate the man-hours required to suppress a fire. The ability to predict the expected development of a fire incident would assist decision makers in allocating firefighting units.

Various fire severity definitions have been used in the literature. For example, Keeley [17] defines fire severity as the degree of post-fire losses and damage. In this work, fire severity is related to the man-hours required for the suppression operation. The fire severity model is also used to create scenarios for multiple fires and classify the impacts. The model inputs are the fire type and the number of assigned firefighting units; the output is the damage level to the facility. The damage level uses an index called the physical mode, which is used by the i2Sim infrastructure interdependencies simulator. i2Sim, which captures the interdependencies existing between infrastructures, is used to model and simulate the physical infrastructure.

The fire severity model is based on the firefighter assessment matrix shown in Table 1. Note that the superscripts for the duration values correspond to the physical modes and color codes in Table 2 (e.g., the superscript 1 corresponds to PM 1 and color code green while the superscript 5 corresponds to PM 5 and color code red). The model has three components: (i) fire type, which classifies fires into four levels based on their severity (catastrophic, critical, marginal and negligible); (ii) required firefighters, which specifies the man-hours required to suppress each type of fire; and (iii) i2Sim physical mode, which expresses the damage level caused by a fire using a color code. Table 2 describes the five color codes used to express the results of firefighter assignments during the simulation.

As an example, consider a scenario with two fire incidents, one critical and one marginal. According to Table 1, critical and marginal fires need 300 and 150 man-hours to be suppressed, respectively. If 20 firefighter units (each with five firefighters) are assigned to each fire, the critical fire is suppressed in 3 hours $(=300 \div(20 \times 5))$ while the marginal fire is suppressed in 1 hour and 30 minutes 
Table 2. Physical mode color codes.

\begin{tabular}{lll}
\hline $\begin{array}{l}\text { Physical } \\
\text { Mode }\end{array}$ & $\begin{array}{l}\text { Color } \\
\text { Code }\end{array}$ & $\begin{array}{l}\text { Unit } \\
\text { Functionality }\end{array}$ \\
\hline PM 1 & Green & $85-100 \%$ \\
PM 2 & Blue & $70-84 \%$ \\
PM 3 & Yellow & $45-69 \%$ \\
PM 4 & Orange & $26-44 \%$ \\
PM 5 & Red & $0-25 \%$ \\
\hline
\end{tabular}

Table 3. Damage assessment table.

\begin{tabular}{lllll}
\hline $\begin{array}{l}\text { Physical } \\
\text { Mode }\end{array}$ & $\begin{array}{l}\text { Color } \\
\text { Code }\end{array}$ & $\begin{array}{l}\text { Level of } \\
\text { Damage }\end{array}$ & Schedule & Description \\
\hline PM 1 & Green & Negligible & Minimal & $\begin{array}{l}\text { No damage but light maintenance } \\
\text { is required for safety }\end{array}$ \\
\hline PM 2 & Blue & Normal & 1 month & $\begin{array}{l}\text { Heavy maintenance and some } \\
\text { equipment repair is required }\end{array}$ \\
\hline PM 3 & Yellow & Marginal & 3 months & $\begin{array}{l}\text { Minor damage and some equip- } \\
\text { ment replacement is required }\end{array}$ \\
\hline PM 4 & Orange & Critical & 6 months & $\begin{array}{l}\text { Major damage and short-term } \\
\text { reconstruction is required }\end{array}$ \\
\hline PM 5 & Red & Catastrophic 12 months & $\begin{array}{l}\text { Significant damage and major } \\
\text { reconstruction is required }\end{array}$ \\
\hline
\end{tabular}

$(=150 \div(20 \times 5))$. The result is a code green for both fires, which from the damage assessment table (Table 3), corresponds to negligible damage with light maintenance required for safety.

In the real scenario, a limited number of firefighting units are available. In particular, assume that a total of 20 units of firefighters are available for both fires. If 16 units are assigned to the critical fire, only four units can be assigned to the marginal fire. As a result, the critical fire is suppressed in 3 hours and 45 minutes $(=300 \div(16 \times 5))$ and the marginal fire in 7 hours and 30 minutes $(=150 \div(4 \times 5))$. The impacts on the production facilities are now code blue and code orange, where code blue implies a normal level of damage with one month of maintenance and code orange means a critical level of damage with six months of maintenance. 


\subsection{Production Loss Model}

The goal of the production loss model is to predict the economic impact of a fire incident based on the firefighter assignments. The model has two components: (i) i2Sim infrastructure interdependencies simulator; and (ii) economic loss model.

Infrastructure Interdependencies Simulator. The i2Sim infrastructure interdependencies simulator provides an environment for representing multiple interdependent critical infrastructures (or production units) [22]. It simulates the effects of resource allocation decisions in real time. i2Sim is an eventdriven, time-domain simulator that uses a cell-channel approach to correlate infrastructure interdependencies. It was selected as the simulator for four main reasons: (i) ability to choose the global simulation objective (e.g., economic, environmental or security); (ii) ability to simulate and produce reasonable results even when data is limited; (iii) ability to simulate multiple infrastructure interdependencies (e.g., water, power and oil) without the assistance of infrastructure experts; and (iv) ability to integrate other simulators and assess the impacts of decisions made in one infrastructure on other infrastructures.

The i2Sim model has three main entities: (i) cells; (ii) channels; and (iii) tokens. Infrastructure components are defined as cells and the connections between them, such as transmission lines and oil pipelines, are defined as channels. Resources and services, such as oil, water and power, are defined as tokens that move between cells (i.e., through channels). The relationship between the input and output of a cell is described by a lookup table. The combinations of cells and channels in the i2Sim model set up a mathematical formulation of the relationships between the infrastructures. A system of discrete time equations is created, which is solved simultaneously for all components at every time step along the timeline to find the operating point of each production cell. The operating states of cells and channels are expressed by their physical modes (PMs) associated with damage levels and resource modes (RMs) associated with the availability of input resources. Each physical mode and resource mode is discretized into five levels, where level 1 is the highest and level 5 is the lowest $[22,23]$.

Economic Loss Model. The plant output corresponds to the materials and/or services produced by the plant. The output of the economic loss model is the economic loss associated with the current operating state of the plant while the fire is evolving dynamically. The production of materials or services is reduced by the fire according to the damage assessed by the fire severity model described above. i2Sim simulates the functionality of the interdependent infrastructures and computes the outputs of all the production facilities. These outputs become the input to the economic loss model, which calculates the projected losses based on the market price.

In this work, the economic impact is calculated using the business interruption cost. This is the cost of the total production loss in a facility due to the 
fire evaluated according to the market value. The overall economic loss is given by:

$$
\text { Overall Economic Loss }=\sum_{t=1}^{T} \sum_{i=1}^{n} \sum_{j=1}^{m}(P \operatorname{Lij}(t) \times V j)
$$

where $t$ is the time of interruption in $T$ time intervals, $n$ is the number of facilities in the infrastructure, $m$ is the number of produced materials and services in each facility, $P L$ is the total lost production of materials and services $j$ in facility $i$, and $V_{j}$ is the market value of materials and services $j$.

Given $U$ firefighting units and $Z$ fire incidents, the problem can be formulated as minimizing the loss in Equation (1) by distributing the firefighting units among the fire incidents. The primary decision variable in this problem is $u_{k}(t)$, which is the number of units assigned to fire $k$ during time interval $t$. Thus, the problem can be formulated as:

$$
\text { Minimize } \sum_{t=1}^{T} \sum_{i=1}^{n} \sum_{j=1}^{m}(P \operatorname{Lij}(t) \times V j)
$$

subject to

$$
\begin{gathered}
\sum_{k=1}^{Z}(t) \leq U \quad \forall t=1,2, \ldots, T \\
u_{k}(t) \leq U \quad k \in Z \quad \forall t=1,2, \ldots, T
\end{gathered}
$$

The first constraint ensures that the total assigned units at every time step is less than or equal to the maximum number of available units. The second constraint ensures that all the assignments are positive integers.

\subsection{Optimization Agent}

Finding the optimal actions to control the behavior of interdependent systems is crucial in many critical infrastructures. In some critical situations, the dynamics of the systems are not completely predictable and it is necessary to quickly find new optimal actions as incidents evolve. Simulation gives a decision maker time to evaluate the options for action. A learning agent F2agent, based on reinforcement learning, was developed and integrated with i2Sim and the fire severity model to create the proposed firefighting decision support system.

In a reinforcement learning algorithm, an agent interacts with its environment to acquire knowledge. The agent decides which action to take and maps each action to a specific situation or state. The agent must maximize a numerical reward signal by choosing among several actions based on the information it receives about its environment at each time step. Often, the agent needs to take a particular sequence of actions to maximize the reward [31]. Reinforcement learning has been applied to solve problems in a variety of disciplines, including scheduling in sensor networks [9], robot learning [19], resource allo- 


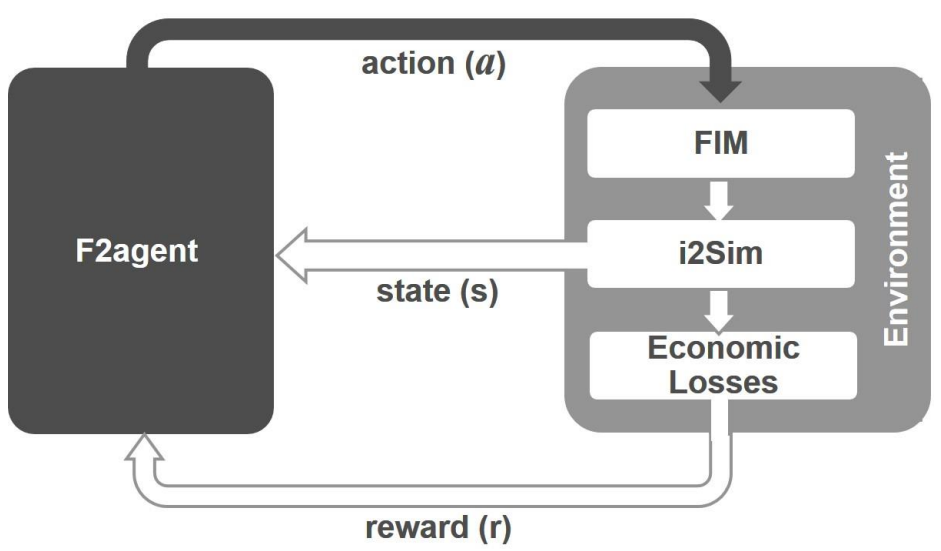

Figure 2. F2agent structure.

cation in business process management [15], learning user behavior in social networks [16] and spacecraft payload processing [33].

Figure 2 shows the structure of F2agent. The objective of F2agent is to minimize the cost of business interruption. The physical mode and resource mode values in the i2Sim model define the state space, which is the set of all states that are reachable from the initial state by a sequence of actions. For example, the state list for two simultaneous fire incidents at two different locations $(x$ and $y)$ is represented as $\left(P M_{x}, R M_{x}, P M_{y}, R M_{y}\right)$ where $P M$ and $R M$ reflect the physical state and the functionality of each entity. As mentioned above, $P M$ and $R M$ are discretized into five levels. Therefore, the total number of states is $5 \times 5 \times 5 \times 5=125$. The output of the economic loss model represents the reward for the different assignments of available firefighting units by the fire severity model.

In this example, it is assumed that the number of available firefighters is 100, which enables the formation of 20 units of five firefighters each. Based on the number of fire incidents, the fire severity model creates a list of possible actions from $A=\{0,20,40,60,80,100\}$. For example, the available actions for each state in the two simultaneous fire incidents are $\{(0,20),(0,40),(0,60),(0,80)$, $(0,100),(20,0),(20,20), \ldots\}$, corresponding to a total of 21 actions.

F2agent begins learning by sensing the current state of the environment reflected by the physical and resource modes of the i2Sim model. It then searches for the current state in a look-up table and stores a Q-value, $Q(s, a)$, for each state-action pair $(s, a)$. Table 4 shows a look-up table sample. The $\mathrm{Q}$-values are initialized randomly. When the agent in state $s_{t}$ takes an action $a_{t}$, it receives a reward $r$, ending up in state $s_{t+1}$, and it then takes an action $a_{t+1}$. The following update is performed [31]:

$$
Q(s, a) \leftarrow\left(1-\alpha_{t}\right) Q(s, a)+\alpha_{t}(r+\gamma Q(\dot{s}, \dot{a}))
$$


Table 4. Look-up table sample.

\begin{tabular}{cc}
\hline (state, action) & Q(state,action) \\
\hline$(1,1,1,1,0,20)$ & 51 \\
$(1,1,1,2,0,40)$ & 620 \\
$(1,1,1,3,0,60)$ & 422 \\
$\ldots$ & $\ldots$ \\
\hline
\end{tabular}

where $0 \leq \gamma \leq 1$ is a discount factor that determines the importance of future rewards and $0 \leq \alpha \leq 1$ is the learning rate $(\alpha=0$ means that the agent does not learn anything while $\alpha=1$ means that the agent only considers the most recent information). The updates continue until the optimal assignment is reached or the stopping criteria is met.

\section{Case Study}

This section describes a case study involving a large petrochemical facility, which is used to demonstrate the utility of the proposed firefighting decision support system.

\subsection{Framework Description}

The petrochemical industry is used as an example of an interdependent infrastructure. It uses oil and natural gas as major raw materials to produce plastics, rubber and fiber materials and other intermediates. The intermediates are converted into thousands of industrial and consumer products that serve as raw materials for other industries. According to Kuwait Finance House (KFH) Research [18], the global petrochemicals market was valued at $\$ 472.06$ billion in 2011 and is expected to reach $\$ 791.05$ billion by 2018 . In terms of volume, the global petrochemicals consumption is expected to reach 627.51 million tons by 2018 [18].

In the petrochemical industry, production processes typically involve a series of physical and chemical reactions. The processes often involve high temperatures and pressures, and other complex technical operations. Due to the large amounts of flammable gases and liquids involved, the petrochemical industry is continuously exposed to the risk of fires, explosions and other accidents.

One of the measures taken to reduce the risk is to restrict the storage of flammable materials. Therefore, these materials flow from one plant to another. The output of a plant becomes the raw material for other plants. This creates strong physical interdependencies between plants. Due to these physical interdependencies, the states of any two plants, Plant A and Plant B, are interrelated. If Plant A supplies Plant B with its required materials, an interruption of a production process in Plant A could result in an interruption 


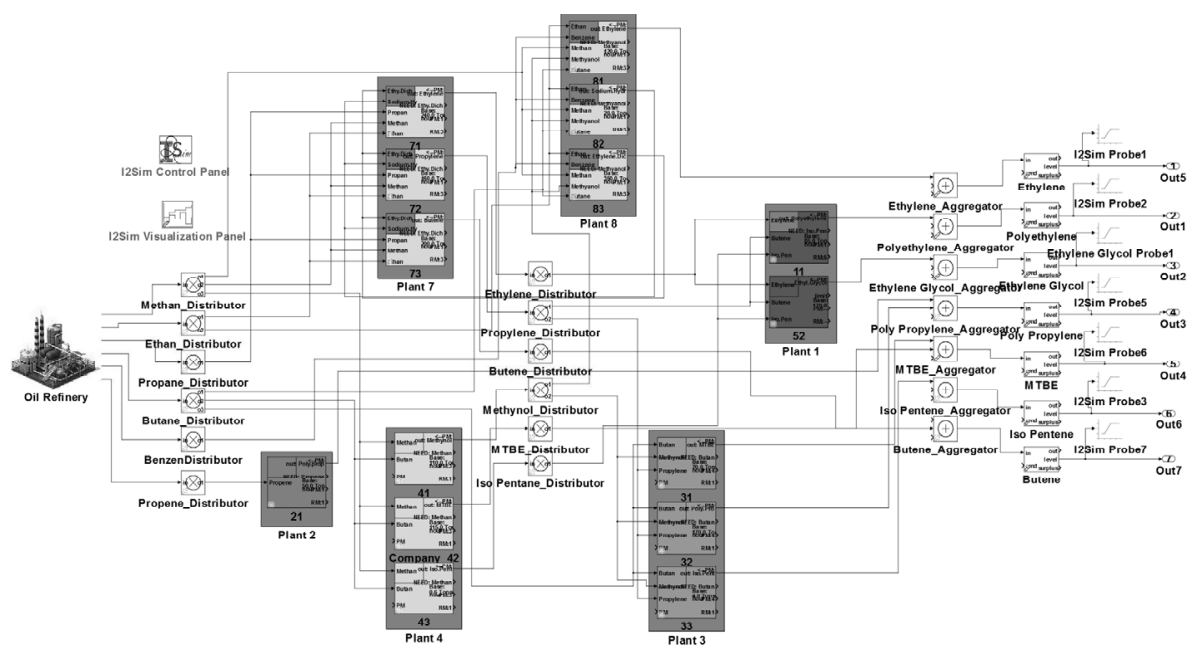

Figure 3. i2Sim model of the petrochemical complex.

in Plant B, Moreover, Plant A might stop producing materials if Plant B is unable to receive the materials as a result of an interruption.

This case study considers an industrial city that has a petrochemical complex comprising fourteen chemical plants that produce a variety of petrochemical materials and 36 pipelines that distribute materials between the plants. The petrochemical complex is modeled based on real data. Figure 3 shows the structure of the complex and the connections between the plants. Only six of the fourteen plants are considered in the model. The industrial city has 100 firefighters, forming 20 units allocated to five fire stations, each station with four firefighting units.

In the case study, two fire incidents, one catastrophic and the other critical, were simulated in Plant 3 and Plant 4, respectively. Table 5 lists the four fire suppression scenarios considered in this work. Scenarios 1 and 2 represent common actions during multiple-fire incidents, which are to allocate firefighting units based on fire size, giving more units to larger fires. Scenario 3 corresponds to a situation where neither fire size nor the optimization agent F2agent are taken into account. Scenario 4 corresponds to a situation where the allocation of units is based on optimized decisions by F2agent. The simulations involved fifteen hours of concurrent suppression operations for the two fire incidents. New assignments of the firefighting units were determined every hour.

The following assumptions were made in the case study:

- No humans were in danger during the incidents, otherwise they would have had priority.

- The environmental impact was not taken into account.

- All the plants had the same level of flammability. 
Table 5. Fire suppression scenarios.

\begin{tabular}{llll}
\hline $\begin{array}{l}\text { Suppression } \\
\text { Scenarios }\end{array}$ & Methodology & Description & Objective \\
\hline Scenario 1 & $70 \%-30 \%$ & $\begin{array}{l}70 \% \text { of the units assigned } \\
\text { to the large fire, } 30 \% \text { to } \\
\text { the other fire }\end{array}$ & $\begin{array}{l}\text { Suppress the large } \\
\text { fire first }\end{array}$ \\
\hline Scenario 2 & $60 \%-40 \%$ & $\begin{array}{l}60 \% \text { of the units assigned } \\
\text { to the large fire, } 40 \% \text { to } \\
\text { the other fire }\end{array}$ & $\begin{array}{l}\text { Suppress the large } \\
\text { fire first }\end{array}$ \\
\hline Scenario 3 & $50 \%-50 \%$ & $\begin{array}{l}50 \% \text { of the units assigned } \\
\text { to each fire }\end{array}$ & $\begin{array}{l}\text { Treat both fires } \\
\text { equally }\end{array}$ \\
\hline Scenario 4 & F2agent & $\begin{array}{l}\text { Agent-based model assigns } \\
\text { units based on the criticality } \\
\text { of each fire }\end{array}$ & $\begin{array}{l}\text { Suppress both fires } \\
\text { with minimum } \\
\text { loss }\end{array}$ \\
\hline
\end{tabular}

- No other organizations (e.g., police and ambulance services) were involved.

- The wind speed and wind direction were uniform in both fire incidents.

\subsection{Results and Analysis}

Simulations were conducted for the four fire suppression scenarios listed in Table 5. Each scenario involved a different assignment sequence of firefighting units to the two fire incidents.

Table 6 shows the simulation results. The proposed firefighting decision support system was able to recognize the critical fire based on the existing interdependencies and suppressed both fires in the least amount of time (Scenario 4) compared with the other three suppression scenarios. Note that Scenario 1 corresponds to the "business as usual" case in firefighting operations, where the majority of available units are assigned to the larger fire. However, the results show that this is the worst decision because it has the longest suppression time.

Effective decisions in response to fire incidents can significantly reduce economic losses. In order to evaluate the impacts of the four fire suppression scenarios on the economic loss, the daily reduction in production of the simulated portion of the petrochemical complex was examined over a one-year period. The daily production income of the complex is about $\$ 41$ million per day during normal operations. Upon comparing this level of income with the income after the two fires were suppressed, it is clear that the decision support system (Scenario 4) achieved the minimum economic loss. Figure 4 shows that the total economic loss in Scenario 4 was just $\$ 800$ million compared with $\$ 5,800$ million for Scenario 1, $\$ 3,000$ million for Scenario 2 and $\$ 1,500$ million 
Table 6. Results for the fire suppression scenarios (U: no. units; T: time).

\begin{tabular}{|c|c|c|c|c|c|c|c|c|c|c|c|c|c|c|c|c|}
\hline \multirow{3}{*}{ Time } & \multicolumn{4}{|c|}{ Scenario 1} & \multicolumn{4}{|c|}{ Scenario 2} & \multicolumn{4}{|c|}{ Scenario 3} & \multicolumn{4}{|c|}{ Scenario 4} \\
\hline & \multicolumn{2}{|c|}{ Fire 1} & \multicolumn{2}{|c|}{ Fire 2} & \multicolumn{2}{|c|}{ Fire 1} & \multicolumn{2}{|c|}{ Fire 2 } & \multicolumn{2}{|c|}{ Fire 1} & \multicolumn{2}{|c|}{ Fire 2} & \multicolumn{2}{|c|}{ Fire 1} & \multicolumn{2}{|c|}{ Fire 2} \\
\hline & $\overline{\mathrm{U}}$ & $\overline{\mathbf{T}}$ & $\overline{\mathbf{U}}$ & $\overline{\mathbf{T}}$ & $\bar{U}$ & $\overline{\mathbf{T}}$ & $\overline{\mathbf{U}}$ & $\overline{\mathbf{T}}$ & $\overline{\mathbf{U}}$ & $\mathbf{T}$ & $\overline{\mathbf{U}}$ & $\mathbf{T}$ & $\overline{\mathbf{U}}$ & $\mathbf{T}$ & $\bar{U}$ & $\bar{T}$ \\
\hline 1 & 6 & 300 & 14 & 600 & 8 & 300 & 12 & 600 & 10 & 300 & 10 & 600 & 16 & 300 & 4 & 600 \\
\hline 2 & 6 & 270 & 14 & 530 & 8 & 260 & 12 & 540 & 10 & 250 & 10 & 550 & 16 & 220 & 4 & 580 \\
\hline 3 & 6 & 240 & 14 & 460 & 8 & 220 & 12 & 480 & 10 & 200 & 10 & 500 & 16 & 140 & 4 & 560 \\
\hline 4 & 6 & 210 & 14 & 390 & 8 & 180 & 12 & 420 & 10 & 150 & 10 & 450 & 12 & 60 & 6 & 540 \\
\hline 5 & 6 & 180 & 14 & 320 & 8 & 140 & 12 & 360 & 10 & 100 & 10 & 400 & 0 & $\mathrm{X}$ & 20 & 500 \\
\hline 6 & 6 & 150 & 14 & 250 & 8 & 100 & 12 & 300 & 10 & 50 & 10 & 350 & & & 20 & 400 \\
\hline 7 & 6 & 120 & 14 & 180 & 8 & 60 & 12 & 240 & 0 & $\mathrm{X}$ & 20 & 300 & & & 20 & 300 \\
\hline 8 & 6 & 90 & 14 & 110 & 8 & 20 & 12 & 180 & & & 20 & 200 & & & 20 & 200 \\
\hline 9 & 6 & 60 & 14 & 40 & 0 & $\mathrm{X}$ & 20 & 120 & & & 20 & 100 & & & 20 & 100 \\
\hline 10 & 20 & 30 & 0 & $\mathrm{X}$ & & & 20 & 20 & & & 0 & $\mathrm{X}$ & & & 0 & $\mathrm{X}$ \\
\hline 11 & 0 & $\mathrm{X}$ & & & & & 0 & $\mathrm{X}$ & & & & & & & & \\
\hline 12 & & & & & & & & & & & & & & & & \\
\hline 13 & & & & & & & & & & & & & & & & \\
\hline 14 & & & & & & & & & & & & & & & & \\
\hline 15 & & & & & & & & & & & & & & & & \\
\hline
\end{tabular}

$\mathrm{X}$ : Fire suppressed.

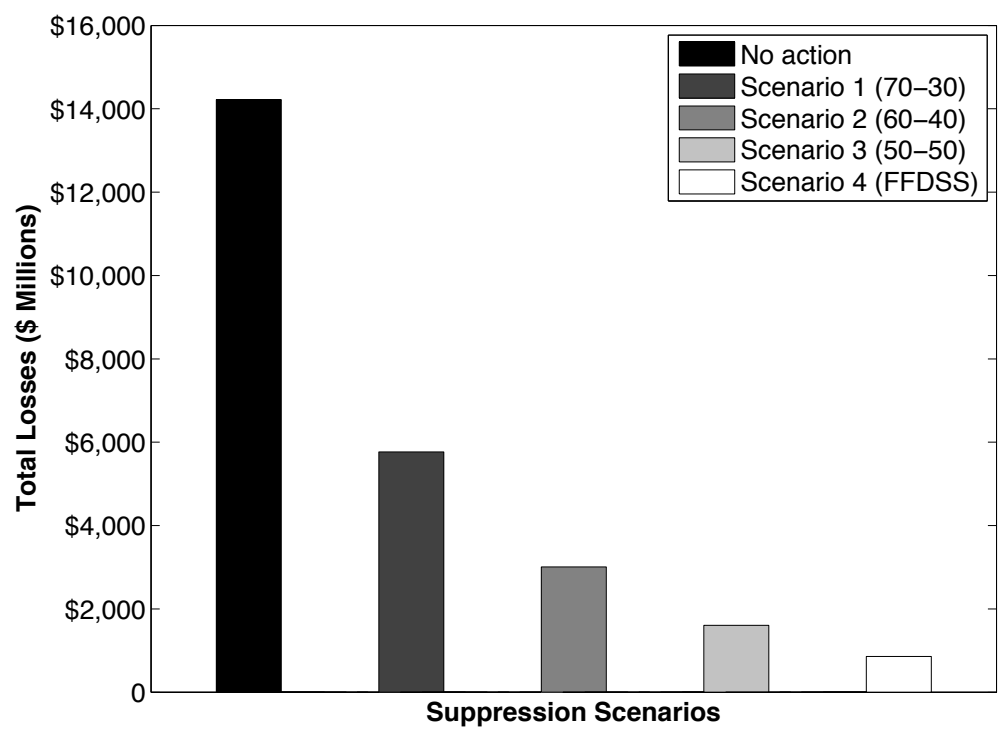

Figure 4. Total losses for the fire suppression scenarios. 


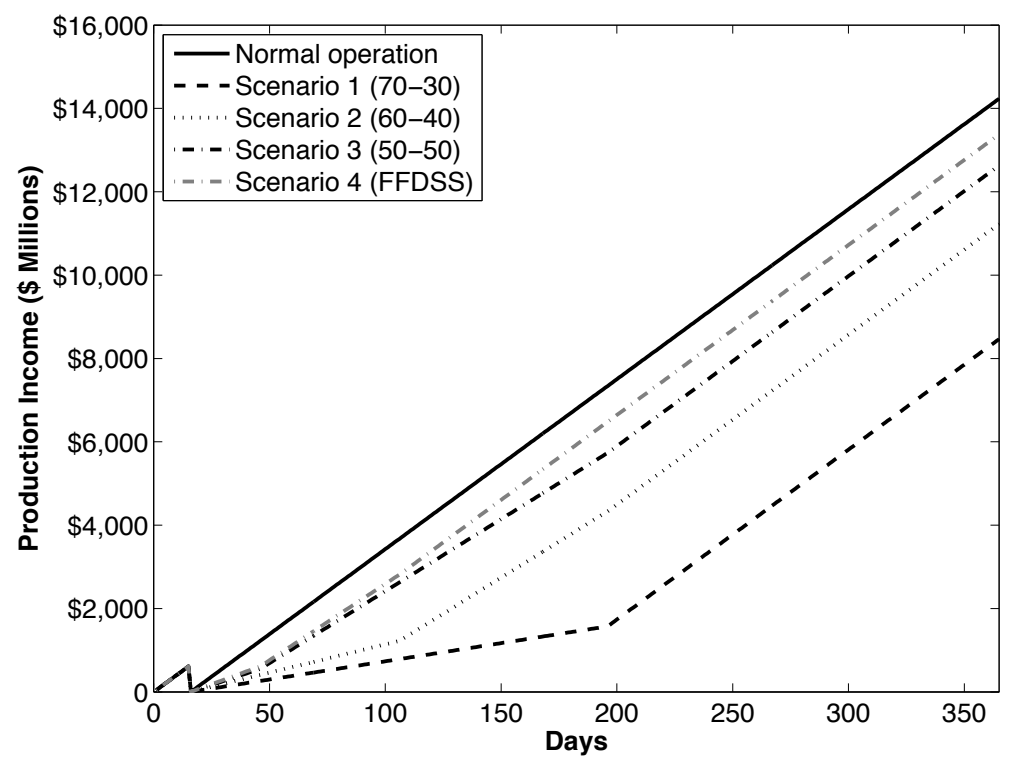

Figure 5. Economic impact on annual production for the suppression scenarios.

for Scenario 3. It is worth noting that the total economic loss when no action is taken is a massive $\$ 14,200$ million.

Figure 5 shows the economic impact on the total income of the petrochemical complex over one year. When the petrochemical complex is operating normally, the annual sales is $\$ 15$ billion. Upon applying the proposed firefighting decision support system, the complex was able to achieve $95 \%$ of its annual sales target (Scenario 4), while the Scenarios 1, 2 and 3 achieved only $61 \%, 80 \%$ and $89 \%$ of the annual sales target, respectively.

\section{Conclusions}

The firefighting decision support system presented in this chapter uses a simulation approach to optimize the allocation of firefighting units in multiplefire incidents. One of the novel features is the consideration of infrastructure interdependencies in the decision making process. The model estimates the damage associated with a fire scenario, calculates the economic loss resulting from the damage and then provides the optimal assignment of the available firefighting units. The joint optimization of the number of assigned firefighting units and the estimated damage significantly reduces the economic loss. The firefighting decision support system can be used before an incident for training and planning, during an incident for decision support or after the incident for evaluating fire suppression strategies. 


\section{Acknowledgements}

The authors wish to thank Dr. Sarbjit Sarkaria for his insightful comments and suggestions. The first author wishes to thank the Ministry of Interior (Civil Defense), Saudi Arabia for its financial support.

\section{References}

[1] P. Andrews, BEHAVE: Fire Behavior Prediction and Fuel Modeling System - BURN Subsystem, Part 1, General Technical Report INT-194, Forest Service, U.S. Department of Agriculture, Washington, DC, 1986.

[2] D. Butry, J. Prestemon, K. Abt and R. Sutphen, Economic optimization of wildfire intervention activities, International Journal of Wildland Fire, vol. 19(5), pp. 659-672, 2010.

[3] D. Calkin, M. Thompson, M. Finney and K. Hyde, A real-time risk assessment tool supporting wildland fire decision making, Journal of Forestry, vol. 109(5), pp. 274-280, 2011.

[4] R. Carvel, Fire Size in Tunnels, Ph.D. Dissertation, Division of Civil Engineering, Heriot-Watt University, Edinburgh, United Kingdom, 2004.

[5] J. Figueras-Jove, A. Guasch-Petit, P. Fonseca-Casa and J. CasanovasGarcia, Simulation and optimization for an experimental environment to wildfire resource management and planning: Firefight project modeling and architecture, Proceedings of the Winter Simulation Conference, pp. 1950-1960, 2013.

[6] M. Finney, FARSITE: A fire area simulator for fire managers, Proceedings of the Biswell Symposium: Fire Issues and Solutions in Urban Interface and Wildland Ecosystems, pp. 55-56, 1995.

[7] Fire and Aviation Management, Fire and Aviation Management Fiscal Year 2006 in Review, FS-885, Forest Service, U.S. Department of Agriculture, Washington, DC, 2007.

[8] J. Fried, J. Gilless and J. Spero, Analyzing initial attack on wildland fires using stochastic simulation, International Journal of Wildland Fire, vol. 15(1), pp. 137-146, 2006.

[9] O. Gul and E. Uysal-Biyikoglu, A randomized scheduling algorithm for energy harvesting wireless sensor networks achieving nearly $100 \%$ throughput, Proceedings of the IEEE Wireless Communication and Networking Conference, pp. 2456-2461, 2014.

[10] R. Haight and J. Fried, Deploying wildland fire suppression resources with a scenario-based standard response model, INFOR: Information Systems and Operational Research, vol. 45(1), pp. 31-39, 2007.

[11] J. Hall, The Total Cost of Fire in the United States, National Fire Protection Association, Quincy, Massachusetts, 2014. 
[12] B. HomChaudhuri, Genetic Algorithm Based Simulation-Optimization for Fighting Wildfires, M.S. Thesis, Department of Mechanical and Materials Engineering, University of Cincinnati, Cincinnati, Ohio, 2010.

[13] X. Hu and L. Ntaimo, Integrated simulation and optimization for wildfire containment, ACM Transactions on Modeling and Computer Simulation, vol. 19(4), article no. 19, 2009.

[14] X. Hu, Y. Sun and L. Ntaimo, DEVS-FIRE: Design and application of formal discrete event wildfire spread and suppression models, Simulation, vol. 88(3), pp. 259-279, 2012.

[15] Z. Huang, W. van der Aalst, X. Lu and H. Duan, Reinforcement learning based resource allocation in business process management, Data and Knowledge Engineering, vol. 70(1), pp. 127-145, 2011.

[16] C. Isbell, C. Shelton, M. Kearns, S. Singh and P. Stone, A social reinforcement learning agent, Proceedings of the Fifth International Conference on Autonomous Agents, pp. 377-384, 2001.

[17] J. Keeley, Fire intensity, fire severity and burn severity: A brief review and suggested usage, International Journal of Wildland Fire, vol. 18, pp. 116-126, 2009.

[18] KFH Research, Saudi Petrochemical: "Trade with Caution," Kuala, Lumpur, Malaysia, 2013.

[19] J. Kober, J. Bagnell and J. Peters, Reinforcement learning in robotics: A survey, International Journal of Robotics Research, vol. 32(11), pp. 12381274, 2013.

[20] Y. Lee, J. Fried, H. Albers and R. Haight, Deploying initial attack resources for wildfire suppression: Spatial coordination, budget constraints and capacity constraints, Canadian Journal of Forest Research, vol. 43(1), pp. 56-65, 2013.

[21] D. Martell, A review of operational research studies in forest fire management, Canadian Journal of Forest Research, vol. 12(2), pp. 119-140, 1982.

[22] J. Marti, Multisystem simulation: Analysis of critical infrastructures for disaster response, in Networks of Networks: The Last Frontier of Complexity, G. D'Agostino and A. Scala (Eds.), Springer, Cham, Switzerland, pp. 255-277, 2014.

[23] J. Marti, J. Hollman, C. Ventura and J. Jatskevich, Dynamic recovery of critical infrastructures: Real-time temporal coordination, International Journal of Critical Infrastructures, vol. 4(1-2), pp. 17-31, 2008.

[24] E. Mihailidou, K. Antoniadis and M. Assael, The 319 major industrial accidents since 1917, International Review of Chemical Engineering, vol. 4(6), pp. 529-540, 2012. 
[25] M. Morais, Comparing Spatially Explicit Models of Fire Spread Through Chaparral Fuels: A New Algorithm Based Upon the Rothermel Fire Spread Equation, M.A. Thesis, Department of Geography, University of California at Santa Barbara, Santa Barbara, California, 2001.

[26] National Fire Protection Association, NFPA 1710: Standard for the Organization and Deployment of Fire Suppression Operations, Emergency Medical Operations and Special Operations to the Public by Career Fire Departments, Quincy, Massachusetts 2010.

[27] L. Ntaimo, X. Hu and Y. Sun, DEVS-FIRE: Towards an integrated simulation environment for surface wildfire spread and containment, Simulation, vol. 84(4), pp. 137-155, 2008.

[28] A. Ollero, J. Martinez-De Dios and B. Arrue, Integrated systems for early forest-fire detection, Proceedings of the Fourteenth Conference on Fire and Forest Meteorology, vol. 2, pp. 1977-1988, 1998.

[29] N. Petrovic, D. Alderson and J. Carlson, Dynamic resource allocation in disaster response: Trade-offs in wildfire suppression, PLOS ONE, vol. 7(4), 2012.

[30] A. Sadeghi-Naini and A. Asgary, Modeling the number of firefighters responding to an incident using artificial neural networks, International Journal of Emergency Services, vol. 2(2), pp. 104-118, 2013.

[31] R. Sutton and A. Barto, Reinforcement Learning: An Introduction, MIT Press, Cambridge, Massachusetts, 1998.

[32] C. Tymstra, M. Flannigan, O. Armitage and K. Logan, Impact of climate change on area burned in Alberta's boreal forest, International Journal of Wildland Fire, vol. 16, pp. 153-160, 2007.

[33] W. Zhang and T. Dietterich, A reinforcement learning approach to jobshop scheduling, Proceedings of the Fourteenth International Joint Conference on Artificial Intelligence, vol. 2, pp. 1114-1120, 1995. 